\title{
СОЦИАЛЬНЫЕ ПРИЧИНЫ И ТЕНДЕНЦИИ РАСПРОСТРА- НЕНИЯ НАРКОМАНИИ В МОЛОДЕЖНОЙ СРЕДЕ (на примере Республики Северная Осетия - Алания, РФ)
}

\section{ЕКАТЕРИНА ФЕДОСОВА}

В законодательстве РФ наркомания определяется как заболевание, обусловленное зависимостью от наркотических средств или психотропных веществ, которые влекут за собой сильную социальную деградацию ${ }^{1}$. Как подчеркивают эксперты Всемирной организации здравоохранения, наркомания представляет серьезную угрозу для человечества. Важно отметить, что, кроме медицинской стороны проблемы, огромную роль играет и ее социально-экономический аспект: наркомания самым существенным образом снижает трудовой, духовный, интеллектуальный, творческий потенциал общества. Подобная форма девиантного поведения чревата противоправными действиями, нарушающими общественные отношения, которые, в свою очередь, обеспечивают защиту значимых социальных ценностей.

Наркотизация населения всегда находилась в центре внимания научно-исследовательского сообщества, но чаще всего это внимание сосредоточивалось на частных вопросах. Так, известный исследователь Я.И. Гилинский в своей работе «Отклоняющееся поведение как социальное явление» в основном акцентирует остроту проблемы наркомании в девиантной среде, тогда как А.А. Габиани интервьюировал наркоманов, проходивших лечение в стационаре, с целью найти наиболее действенные методы лечения наркозависимых и рассматривал проблему по преимуществу с медицинской стороны ${ }^{2}$. Некоторые российские исследователи в своих трудах стремятся проанализировать проблему наркомании комплексно; так, Я.Н. Нахимова и Г.Ф. Ромашкина посвятили свою работу ${ }^{3}$ специфике социальных установок молодежи на потребление наркотиков и обосновали необходимость профилактики в образовательной среде; этот вопрос остается актуальным, поскольку основной оборот наркопотребления и наркораспространения приходится на несовершеннолетних в учебных заведениях.

1 Федеральный закон "О наркотических средствах и психотропных веществах" от 08.01.1998 N 3-Ф3

2 Габиани А. А. На краю пропасти: наркомания и наркоманы. М.: Мысль, 1990.

${ }^{3}$ Нахимова Я. Н., Ромашкина Г.Ф. Социальные установки молодежи на употребление наркотиков и профилактика наркомании // Образование и наука. 2017. №19(6), с. 138-160 // https://doi.org/10.17853/1994-5639-2017-6-138-160 
Еще одна интересная работа на данную тему демонстрирует степень и уровень наркотизации молодежи, в том числе несовершеннолетних ${ }^{4}$.

Актуальность темы в первую очередь обусловлена обострением ситуации, что порождает необходимость комплексных социологических исследований, посвященных социальному контролю, эффективности профилактических программ, концептуальным основаниям социального механизма, способного противодействовать наркотизации населения, поиску оптимальных средств его модернизации. Сегодня в России регулярно употребляют наркотики 5,99 млн. человек, официальная статистика по наркомании приводит значительно меньшую цифру - 500 тыс., однако это те, кто добровольно встал на медицинский учет. Между тем медицинские учреждения могут стационарно пролечить за год не более 50 тыс. человек 5

От общего числа наркоманов в России по статистике:

- $20 \%$ - школьники;

- 60\% - молодежь в возрасте 16-30 лет;

- $20 \%$ - лица более старшего возраста.

Средний возраст приобщения к наркотикам в России составляет по статистике 15-17 лет, резко увеличивается процент употребления наркотиков детьми 9-13 лет. Основными очагами распространения наркотиков в городах являются школы и места развлечения молодежи - дискотеки и клубы. По данным Федеральной службы РФ по контролю за оборотом наркотиков каждый наркоман вовлекает в употребление наркотиков примерно 13-15 человек. Число смертей от употребления наркотических веществ за последние годы выросло в 12 раз, а среди детей - в 42 раза. Приблизительная продолжительность жизни с момента начала употребления наркотических веществ составляет в среднем 4-5 лет. В связи с этим особую актуальность приобретает разработка комплексной региональной системы сбора и анализа данных о наркоситуации, научно обоснованная подготовка информационной почвы для эффективного прогнозирования и принятия адекватных управленческих решений по противодействию незаконному потреблению и обороту наркотиков. В практическом, прикладном плане социологическое изучение наркоситуации актуально для текущего и стратегического планирования действий органов власти на национальном, региональном и муниципальном уровнях.

В связи с этим автором в сентябре-ноябре 2020 года был проведен анкетный опрос, определяющий масштаб незаконного потребления наркотиков и факторы, оказывающие влияние на наркоситуацию в Республике

${ }^{4}$ Monitoring the Future Survey: High School and Youth Trends. December 2017. URL: https://www.drugabuse.gov/publications/drugfacts/monitoring-future-survey-high-schoolyouth-trends

${ }^{5}$ Статистика по наркозависимым в России в 2019 г.: последние цифры исследований // https://stopz.ru/informaciya/narkomaniya/statistika-po-narkozavisimym-v-rossii/ 
Северная Осетия - Алания ${ }^{6}$. Выборочная совокупность исследования сбалансирована и в целом отражает социально-демографическую ситуацию в республике 7 . Были опрошены респонденты всех социальных групп, различной этнической принадлежности, с разным семейным положением, уровнем образования, характера работы и материального достатка, что в итоге обеспечило репрезентативность полученных результатов.

Чтобы точнее представить картину в Северной Осетии - Алания, требуется дать общую оценку ситуации с наркоманией в регионе. По сведениям Республиканского наркологического диспансера по состоянию на 1 января 2020 года здесь зарегистрировано 3236 человек с наркологическими заболеваниями; для сравнения: в 2017 г. - 3171, в 2016-м - 3261, в том числе 798 с диагнозом «наркомания» (в 2017 г. - 777, в 2016-м - 820), 2438 с диагнозом «употребление наркотических средств с вредными последствиями» (в 2017 г. - 2394, в 2016-м - 2441).

Возрастной состав зарегистрированных лиц распределился следующим образом:

с диагнозом «наркомания»:

- от 0 до 17 лет - 0;

- от 18 до 19 лет - 0;

- от 20 до 39 лет - 384 человека;

- от 40 до 59 лет - 392 человека;

- старше 60 лет - 22 человека;

С диагнозом «употребление наркотических средств с вредными последствиями»:

- от 0 до 14 лет - 0;

- от 15 до 17 лет - 9 человек;

- от 18 до 19 лет - 5 человек;

- от 20 до 39 лет - 1514 человек;

- от 40 до 59 лет - 901 человек;

- старше 60 лет -9 человек $^{8}$.

Необходимо отметить, что приведенные выше цифры не в полной мере отражают реальность, так как по данным Всемирной организации здравоохранения на медицинский учет становится только каждый 50-й наркоман, под контроль попадают лишь 10\% от общего числа больных

\footnotetext{
${ }^{6}$ Общая выборочная совокупность по Республике Северная Осетия - Алания составила 500 чел. $(\mathrm{N}=500)$. Расчет выборочной совокупности производился на основе численности молодого населения городских округов, муниципальных районов, городских и сельских поселений 2019 года: Федеральная служба государственной статистики, URL: https://rosstat.gov.ru/folder/13807.

7 Анкетный опрос проводился во Владикавказе и во всех муниципальных районах республики: Алагирском, Ардонском, Правобережном, Пригородном, Моздокском, Кировском, Дигорском и Ирафском. При проведении опроса приоритет отдавался молодежи от 14 до 30 лет. По возрастным группам респонденты распределились следующим образом: 46,2\% - от 14 до 17 лет, 17,2\% - от 18 до 20 лет, 19,8\% - от 21 до 25 лет, 16,9\% - от 26 до 30 лет.

${ }^{8}$ Доклад Главы РСО - Алания В.З.Битарова о мониторинге наркоситуации за 2020 год. URL: http://alania.gov.ru/pages/7708
} 
наркоманией. Хотя бы раз пробовали наркотики 20\% населения в возрасте от 11 до 40 лет (14,5 млн. человек). Среди мужчин - 28\%, среди женщин $-13 \%{ }^{9}$.

Кроме того, распространению наркомании способствовал такой фактор, как проникновение традиций и обычаев преступной среды во многие неформальные группы подростков и молодежи с противоправной направленностью. Если в старших молодежных группах выбор наркотика определяется поиском способов достижения эйфории, то в младших возрастных группах одним из основных мотивов является любопытство, связанное с действием психотропных препаратов, вызывающих галлюцинации. Общеизвестно, что у подростков социализация происходит в группе сверстников, часто решающим фактором оказывается мода, распространение информации, социальных норм, способов самоутверждения. У детей и подростков ведущим оказывается групповой мотив - следование образу действий группы, подчинение моде, что выступает серьезной причиной роста интереса к наркотикам.

Проблема наркомании в Северной Осетии - Алании в первую очередь связывается со сложным социально-экономическим положением в республике, которое выступает одним из побудительных мотивов вовлечения молодежи в употребление и распространение наркотических веществ.

В ходе исследования респондентам было предложено выбрать не более пяти наиболее существенных проблем, стоящих в 2020 году перед республикой и требующих первоочередного решения. Их оценки экономической ситуации в республике показали отрицательную динамику основных макроэкономических показателей. В число наиболее актуальных проблем молодые люди включают безработииу, качество медицинского обслуживания, бедность, рост иеен на предметы первой необходимости и продукты питания, высокий уровень преступности, алкоголизм и наркотизацию населения (рис.1).

Обратим внимание, что на распространенность наркомании в месте проживания указывает, прежде всего, городская молодежь, а также молодежь в возрасте 18-25 и 26-30 лет. Эта ситуация объясняется объективными факторами - большим количеством представителей т.н. «групп риска», т.е. распространение наркотических веществ идет за потенциальным потребителем. Также одним из массовых путей приобретения является механизм «закладок», поиск которых происходит порой в публичной плоскости и регулярно становится достоянием большого числа молодых людей, в том числе и за счет сети Интернет (фото, видео о «странном» поведении постоянно выкладываются гражданами в социальные сети).

\section{M., 2006.}

${ }^{9}$ Состояние и динамика наркоситуации среди населения России в возрасте от 11-40 лет. 


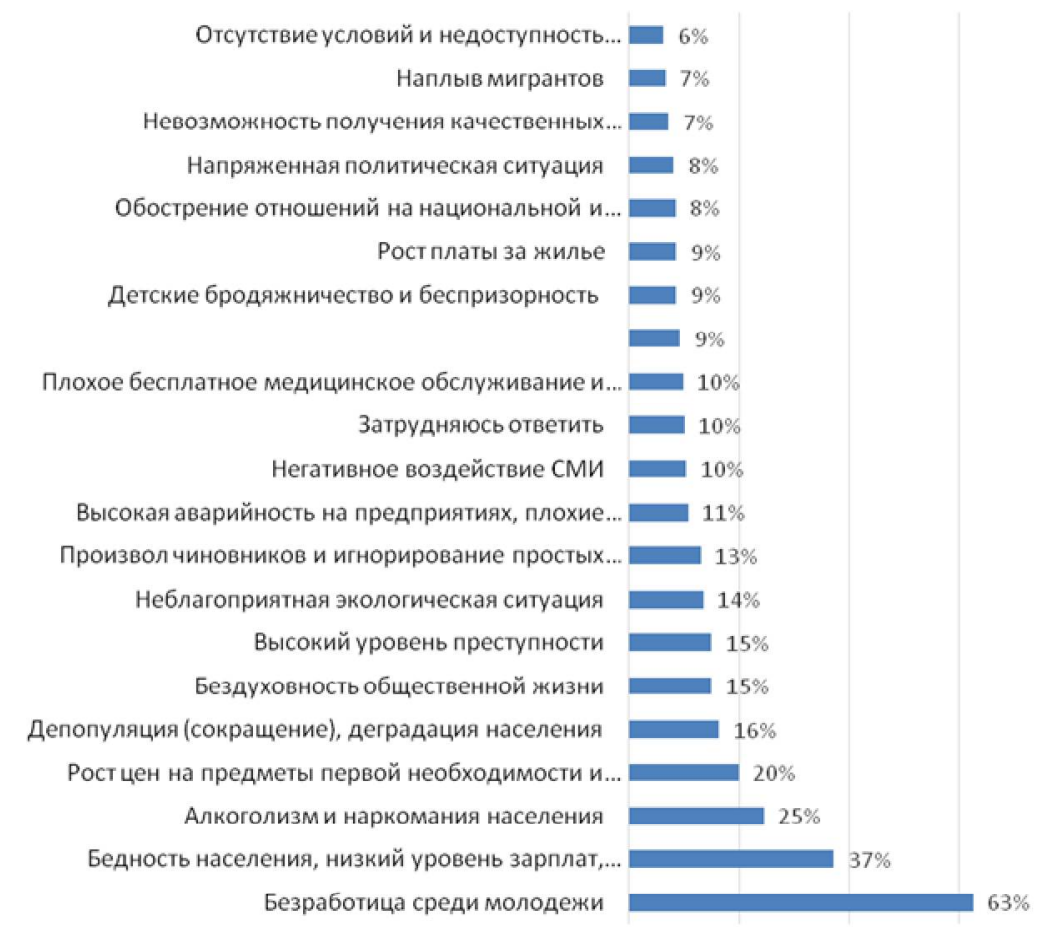

По результатам опроса был составлен рейтинг основных причин, ведущих к распространению наркотиков. В первую очередь молодые люди отмечают социальное неблагополучие - 41\%, моральную деградащию общества, вседозволенность - 24\% и безработииу - 21\%. Среди основных причин распространения наркомании в РСО - Алания респонденты видят отсутствие организованного культурного досуга: большинство опрошенной молодежи (64\%) считает, что в их населенных пунктах недостаточно возможностей интересно проводить свободное время; такова объективная предпосылка для приобщения к употреблению наркотических веществ при наличии основных факторов - доступность приобретения, социальное окружение и т.д.

В ходе исследования удалось определить основные места сбыта наркотических средств, которые во многом связаны с интересами и соответственно местами локализации респондентов: социальной коммуникации, обмена информационными, психологическими и материальными ресурсами (рис. 2). Большинство респондентов все же затруднились ответить на вопрос о местах приобретения наркотических веществ, что говорит об эффективности работы, проводимой в сфере контрпропаганды наркотиков, которая сформировала в молодежном сознании негативное отношение к наркотикам и позитивное отношение к мерам по противодействию их распространению. 
Рисунок 2

Места приобретения наркотических веществ в РСО-А, \% (по причине того, что данный вопрос являлся многозначным и респонденты имели возможность выбрать более одного варианта ответа, суммарный процент составляет более $100 \%$.).

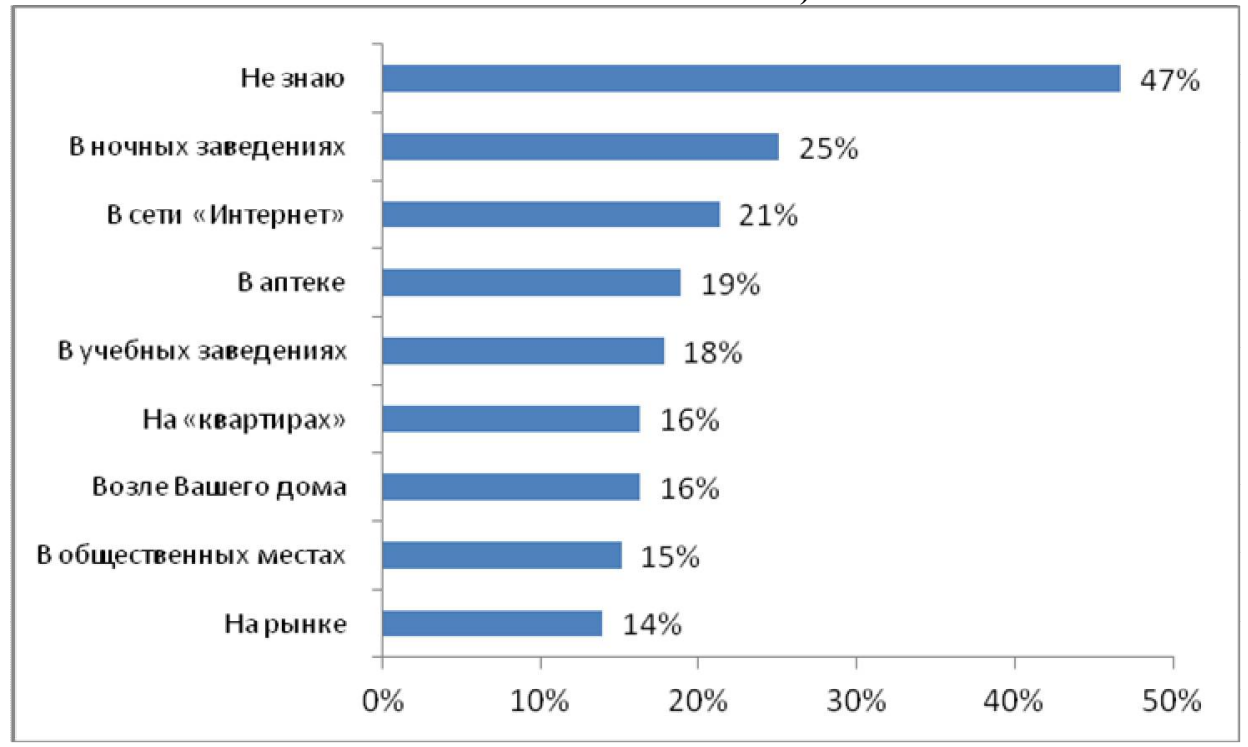

В плане контактов продолжает наблюдаться отторжение наркозависимых из круга знакомых респондентов. Большинство опрошенных указали, что не имеют в своем кругу таких знакомых, а также тех, кто предлагает попробовать наркотические средства (73\%). Тем не менее некоторые респонденты все же указали, что в кругу их друзей и близких есть люди, которые употребляют наркотические вещества (18\%). 7\% опрошенных утверждают, что «в кругу их друзей и знакомых есть много таких».

В целом данный результат ожидаем и вероятнее всего объясняется тем, что именно молодежь является «группой риска», которая в силу своего возраста и нестабильности социального статуса более всего подвержена внушению и ориентирована на заимствование тиражируемых образцов социального поведения. Поскольку тиражирование и подражание реализуется посредством массовой культуры и акций в Интернете, весьма значимой становится система профилактических мер, рассчитанная по преимуществу на молодежь и подростков и учитывающая интересы и перспективы данной возрастной группы. Так, на вопрос о том, предлагали ли молодым людям когда-либо попробовать наркотические средства, 73\% респондентов ответили отрицательно, однако $21 \%$ дали положительный ответ. Рост новой инфраструктуры сбыта наркотиков может быть оценен на основании соотношения наркозависимых и лиц, пробовавших наркотики однократно. В условиях социальной и психологической нестабильности, особенно в так называемых переходных условиях (переходный возраст - один из видов таких переходов в жизни человека), у индивидов возникает потребность в 
граничных ощущениях, ложно определяемых как некое преодоление социальных границ и норм существования. Вкусить «запретный плод», в данном случае попробовать наркотики, - это протестная форма социального поведения, выводящая человека в состояние квазисвободы.

Часть индивидов остается наркозависимыми, а часть больше не прикасается к наркотикам. Для уточнения и детализации данных исследования респондентам был поставлен вопрос о гипотетической ситуации, когда им предлагают наркотические средства (рис. 3).

Реакция респондентов на предложение попробовать

Рисунок 3 наркотические средства, \%

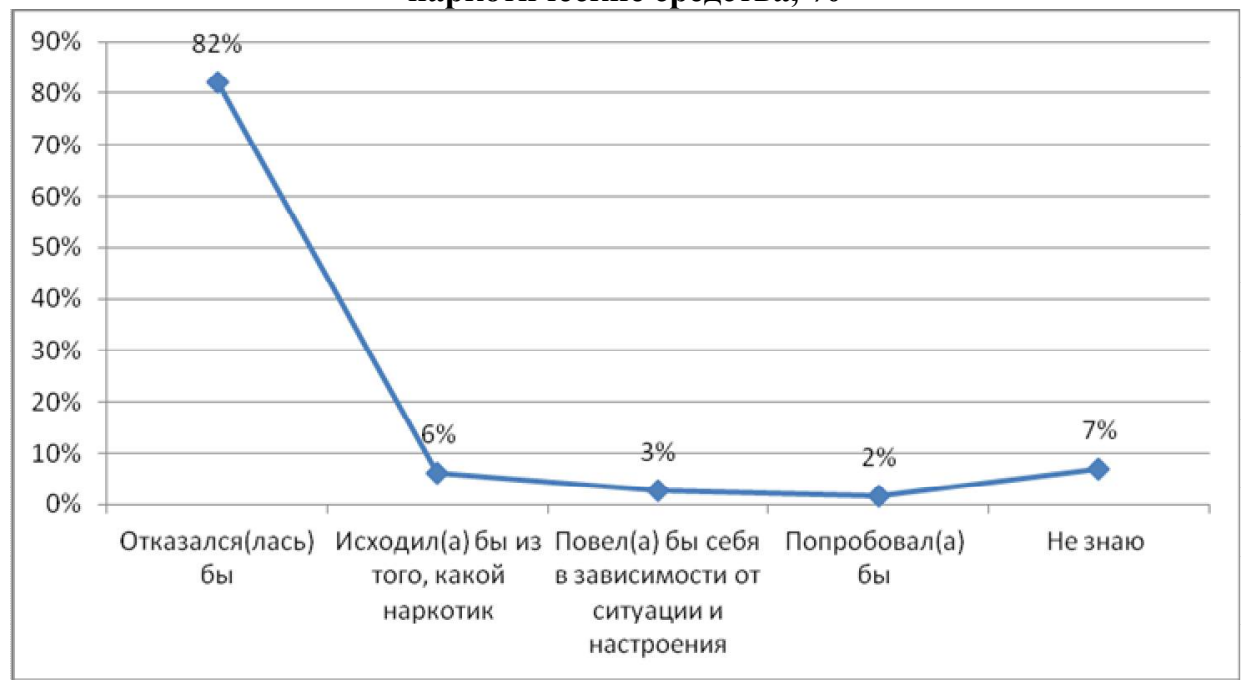

Данные по исследованию в целом весьма положительны, так как 82\% опрошенных отказались бы употреблять наркотические средства. Вместе с тем следует учесть, что вопрос предполагает определенную нормативную санкционированность за положительный ответ, что могло повлиять на степень искренности респондентов.

Одним из решающих моментов профилактики наркопотребления должно стать ослабление дифференциации наркотических средств на «легкие» и «тяжелые». Такое разделение постоянно воспроизводится в общественном мнении институтами массовой культуры. Вопрос переходит в плоскость работы с подростковой и молодежной группами населения с неустойчивым социальным и психологическим статусом.

Анализ наркоситуации показывает, что на территории республики, как и прежде, наиболее распространенными и доступными остаются наркотические средства растительного происхождения и их производные, такие, как марихуана (анаша) (4\%), курительные смеси наркотического характера (14\%), семена «дурман-травы» (15\%). Причиной служат очаги дикорастущей конопли - сырья для изготовления наркотических средств 
каннабисной группы. Также впервые за время мониторинга первую строчку занимают лекарственные препараты (17\%) и глазные капли (13\%).

Молодежь школьного возраста (14 - 17 лет) и старше (18 - 30 лет) указывала «легкие» наркотические вещества - марихуану и курительной смеси (15\%), а также «веселящий газ» (2\%) и маковую соломку (12\%). Респонденты старшей возрастной группы, употребляющие наркотики, назвали также «тяжелые»: соли (14\%), эфедрон, героин (12\%), опий (2\%).

Доминирующая мотивация попробовать наркотики - любопытство (15\%, снятие напряжения - 12\%, а также проблемь в семье - 8\%. Очень показателен ответ «стремление быть, как все», это ключевой фактор для 8\% респондентов. Вариант «от нечего делать» выбрали 8\%, что говорит о новых реалиях социального взаимодействия; в социуме возникает и развивается новый образ поведения, создающий психологически нездоровую атмосферу.

Стремление «получить удовольствие» стало ключевым для 7\% употребляющих наркотические вещества. Отметим: процент тех, кто мотивирует тягу к наркотикам «уходом от личных проблем» - 7\% (в 2019 г - 0,3\%), «избеганием проблем в семье», потерянностью и одиночеством, выключенностью из реального социокультурного взаимодействия, значительно вырос. Значит, для тех, кто стремится попробовать или употребляет наркотические средства, нет доступа к моделям конструктивного поведения, здорового образа жизни, а социальное окружение выражает безразличие. В первую очередь это касается отношения к детям в семье, что накладывает особую ответственность на работу с семьей в рамках профилактики наркомании.

Результаты опроса показали: большая часть опрошенных (55\%) считает, что наркотическую зависимость можно пресечь по собственной воле. Данный показатель можно считать положительным, ибо этот вариант ответа предполагает позитивное и ненасильственное решение проблемы наркотической зависимости. С другой стороны, то, что до половины респондентов полагает, что с болезнью может справиться сам наркозависимый, демонстрирует отсутствие достоверной информации о наркозависимости среди значительной части опрошенных. Особенно характерно это для молодежи, в среде которой принято говорить о свободе при употреблении так называемых «легких наркотиков».

Отсутствие рационального подтверждения моделей здорового конструктивного образа жизни в СМИ (согласно анализу компании «Медиалогия», по теме наркомании в российских СМИ за год зафиксировано 168791 сообщений $^{10}$ ), целенаправленных программ на телевидении отдает молодежь влиянию чувственно-эмоциональной зависимости от нестабильной жизни. Данная установка в общественном мнении активизирует представ-

10 Наркомания в России: мониторинг. URL: https://wciom.ru/analytical-reviews/ analiticheskii-obzor/narkomaniya-v-rossii-monitoring 
ления о том, что наркотики можно употреблять с низкой периодичностью или хотя бы попробовать, а потом отказаться от них. Однако летальные исходы от употребления наркосодержащих веществ и их освещение в СМИ склоняют респондентов к мнению о пользе здорового образа жизни.

Результаты опроса по наркоситуации в муниципальных районах республики показали многоаспектность рассматриваемой проблемы. Наркомания в регионе является одной из основных угроз здоровью населения, а также возбудителем и катализатором других социальных и экономических проблем. И комплексные меры, включающие социологические исследования и мониторинги, помогут в разработке действенных и обоснованных путей борьбы с этой серьезной общемировой проблемой.

Ключевые слова: наркоситуащия, предотвращение, проблемы молодежи, наркозависимость, социальные причины наркомании

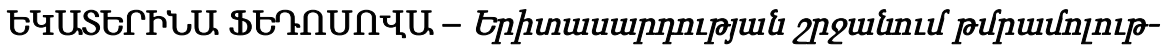

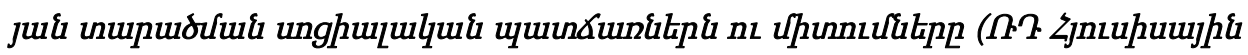

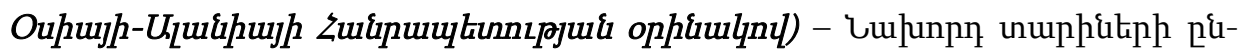

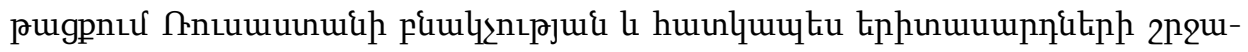

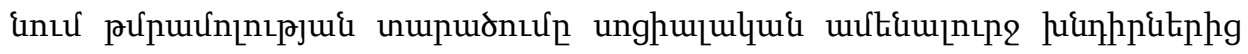

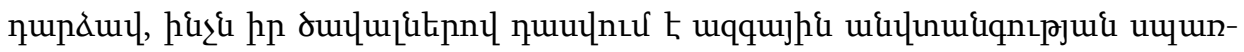

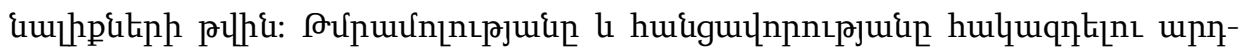

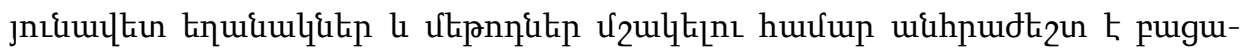

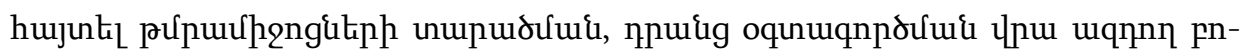

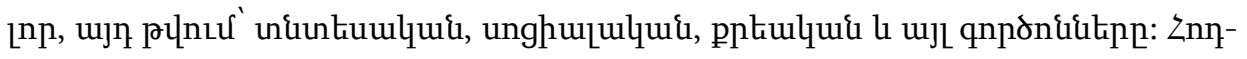

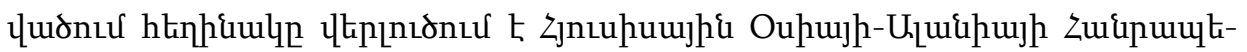

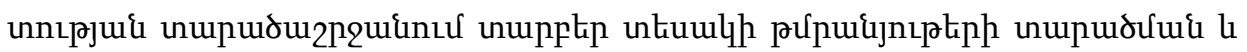

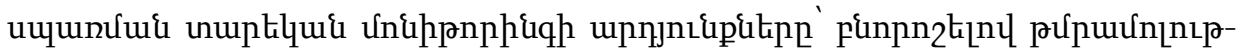

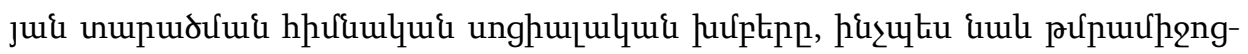

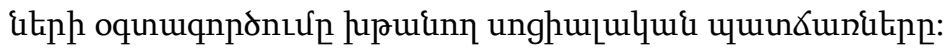

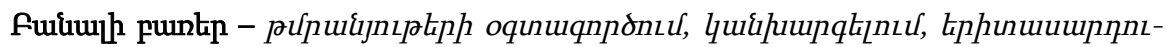

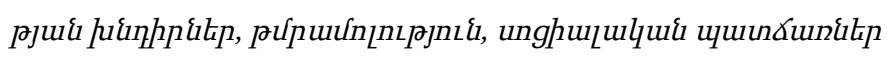

EKATERINA FEDOSOVA - Social causes and tendencies of drug spreading among youth (on the case of the Republic of North Ossetia-Alania, Russian Federation) - Over the past years, the drug addiction of the population of Russia and especially young people is one of the most serious social problems, the scale of which made it a threat to the national security. In order to develop effective ways and methods of counteracting drug addiction and crime, it is necessary to know the characteristics of all economic, social, criminal and other factors influencing the drug situation. In the article 
the author analyzes the results of the annual monitoring of the consumption and distribution of various types of drugs in the region of the Republic of North Ossetia - Alania, identifying the main social groups of drug addictions as well as social causes which stimulate drug addiction among youth.

Keywords: drug situation, prevention, youth problems, drug addiction, social causes 


\begin{abstract}
Over the past years, the drug addiction of the population of Russia and especially young people is one of the most serious social problems, the scale of which made it a threat to national security. In order to develop effective ways and methods of counteracting drug addiction and crime, it is necessary to know the characteristics of all economic, social, criminal, and other factors influencing the drug situation. In the article, the author analyzes the results of the annual monitoring of the consumption and distribution of various types of drugs in the region of the Republic of North Ossetia - Alania, identifying the main social groups of drug addictions as well as social causes which stimulate drug addiction among youth.
\end{abstract}

Keywords: drug situation, prevention, youth problems, drug addiction, social causes

\title{
About Authors
}

Ekaterina Fedosova - Head of Department of Sociological Research in the Committee of the Republic of North Ossetia-Alania on Youth Affairs, Russian Federation E mail: fedosova-e@inbox.ru

\section{REFERENCES}

Gabiani, A.A. (1990). Na krayu proposti: narkomania i narkomany. Moscow, Mysl' Nahimova, Ya. N. \& Romashkina, G.F. (2017). Social'nye ustanovki molodeji na upotreblenie narkotikov i profilaktika narkomanii. Obrazovanie i nauka. No 19(6), 138-160 DOI: https://doi.org/10.17853/1994-5639-2017-6-138-160 